limited. Variation in outcome is not constant reason to restrict cochlear implantation in children with post meningitis deafness.

\section{THE SPECTRUM OF GENITAL MEDIAN RAPHE ANOMALIES AMONG INFANTS UNDERGOING RITUAL CIRCUMCISION}

doi:10.1136/archdischild-2012-302724.1597

MB Fahmy. Pediatric Surgery, Al Azher, Cairo, Egypt

Background This prospective study designed to collect data from all babies coming to do ritual circumcision in our center for any associated congenital anomalies in their genitalia.

Objective To evaluate the extent, spectrum of genital median raphe GMR anomalies and its impaction on the normal baby life and also its effect on the circumcision outcome.

Materials and Methods 2880 babies aged from one day to 7 weeks were examined in a period of 6 years, from 2006 to 2011, all doubtful cases were reevaluated and cases with GMR anomalies were investigated for detection of other congenital anomalies and enrolled in the study.

Results 57 cases of GMR anomalies among 2880 examined babies with overall incidence of $2 \%, 18$ of them had hypospadias, 5 had renal anomalies and 3 had limb anomalies. Circumcision postponed in 37 cases, where further investigations done, but routine circumcision carried on in 20 in spite of the presence of GMR anomalies.

Conclusion It is crucial to examine every baby coming for circumcision to detect any obvious or hidden congenital genital anomalies, congenital anomalies of median genital raphe are not so rare and some of these anomalies may necessitates surgical correction, and commonly accompanied with urinary tract anomalies.

\section{TRANS-UMBILICAL LAPAROSCOPIC-ASSISTED APPENDECTOMY: A RETROSPECTIVE STUDY}

doi:10.1136/archdischild-2012-302724.1598

G Scirè, V Guerriero, FS Camoglio, L Giacomello. Department of Surgery, Unit of Paediatric Surgery, University of Verona, Verona, Italy

Introduction Laparoscopic appendectomy (LA) in children is considered a safe and useful procedure compared with the open $(O)$ appendectomy. Several variations of the LA have been described. The trans-umbilical laparoscopic-assisted appendectomy (TULAA) has been considered as a reliable and effective technique. We report our experience in the treatment of the acute appendicitis with TULAA approach.

Materials and Methods We analyzed records of patients underwent appendectomy in our Department from November 2009 to February 2012. Every procedures have been completed using all techniques, according to consultant's choice. Outcomes analysis included: sex, age, weight, operator (consultant or trainer), conversion to $\mathrm{O}$ or LA technique, surgical time, length-of-stay, antibiotic and analgesic post-operative therapy, short and long-term complications, histological finding. Results are presented as values range and their averages.

\section{Results}

Conclusions In our study there is a clear evidence that TULAA is an effective and safe procedure.

It can be used for all kind of appendicitis, with a low-rate of conversion. Additionally, thanks to a rapid learning-curve, it can be performed by a trainer, even if not completely skilled in the LA.

\section{PERI- AND POSTOPERATIVE COMPLICATIONS OF 215 CASES OF INGUINAL HERNIA IN CHILDREN}

doi:10.1136/archdischild-2012-302724.1599

CS Berghea Neamtu. Pediatric Clinic Hospital Sibiu, Lucian Blaga University of Sibiu, Sibiu, Romania

Background The cure of inguinal hernia in children consists of high ligation of hernial sac, generally evolving with few complications.

Aim The evaluation of casuistry structure and evaluation of periand postoperative complications in children.

Method Retrospective analytical study for a period of three years includes case studies which required high ligation of the hernia sac (procesus vaginalis)

Results The 214 cases were stratified according to:

1. Location: left side 29 hernias (13.5\%); bilateral 4 (1.8\%); right side $181(84.5 \%)$ cases;

2. Age: $1-3$ years, 70 (32.7\%); 4-6 years, 71 (33.1\%); 7-12 years, $62(28.9 \%)$; $13-18$ years, 11 cases $(5.1 \%)$;

3. During hospitalization: $\leq 3$ days, 65 (30.3\%); 4-5 days, 103 $(48.1 \%) ; \geq 6$ days, 46 cases $(21.4 \%)$

4. Gender: Male $176(82.2 \%)$, Female 38 cases $(17.7 \%)$

Diagnosis at Discharge No occlusion and gangrene 196 (91.6\%); with occlusion and gangrene $9(4.2 \%)$, without occlusion with gangrene $5(2.3 \%)$, bilateral hernias without occlusion and gangrene 4 cases $(1.8 \%)$.

Perioperative and Postoperative Complications Strangulated $8(3.7 \%)$ - nonreductible 2 , edema $3(1.4 \%)$, spermatic cord hematoma $2(0.9 \%)$, paralytic ileus $2(0.9 \%)$, erythema $21(9.8 \%)$.

Conclusions Inguinal hernias are found more common in boys, on the right side, in preschool (1-6 years) and school children (7-12 years).

Most cases were within the duration of hospitalization between 2-5 days.

Most hernias were without occlusion and gangrene.

Complications, fewer in number and diversity as in adult patients, are in order of frequency: erythema, strangulation/

Abstract 1598 Table 1 Results 1

\begin{tabular}{|c|c|c|c|c|c|c|c|c|c|}
\hline & AGE & SEX (F/M) & WEIGHT (KG) & TIMING (MIN) & CONVERSION & ANTIBIOTIC & $\begin{array}{c}\text { ORAL } \\
\text { ANALGESIA }\end{array}$ & IV ANALGESIA & LENGHT-OF-STAY \\
\hline TULAA (55) & $9.8(4-14)$ & $34 / 21$ & $36.9(14.5-70,0)$ & $61.0(25-135)$ & 6 (1 LA- 50$)$ & 54 & 26 & 36 & $3.7(2-14)$ \\
\hline LA (42) & $10.5(3.5-15)$ & $19 / 23$ & $41.3(15.0-72,5)$ & $72.1(20-275)$ & $1(0)$ & 39 & 24 & 28 & $4.8(2-13)$ \\
\hline
\end{tabular}

Abstract 1598 Table 2 Results 2

\begin{tabular}{lcccccc}
\hline & $\begin{array}{c}\text { INTRA-OP } \\
\text { COMPLICATIONS }\end{array}$ & $\begin{array}{c}\text { POST-OP } \\
\text { COMPLICATIONS }\end{array}$ & OPERATOR (C/T) & IPEREMIC & PHLEGMONOSUS & GANGRENOSUS \\
\hline TULAA (55) & 2 & 4 & $37 / 18$ & 32 & 17 & 3 \\
LA (42) & 0 & 2 & $39 / 3$ & 22 & 9 & 5 \\
\hline
\end{tabular}

